\title{
Effect of oil palm shell treatment on the physical and mechanical properties of lightweight concrete
}

\author{
Yasmine Binta Traore ${ }^{\mathrm{a}}$, Adamah Messan ${ }^{\mathrm{a}, *}$, Kinda Hannawi ${ }^{\mathrm{b}}$, Jean Gerard ${ }^{\mathrm{c}}$, William Prince ${ }^{\mathrm{b}}$, \\ Francois Tsobnang ${ }^{a}$ \\ a Institut International d'Ingenierie de l'Eau et de l'Environnement (2iE), Laboratoire Eco Matériaux de Construction (LEMC), Rue de la Science, 01 BP 594 Ouagadougou 01, \\ Burkina Faso \\ b Institut National des Sciences Appliquées de Rennes (INSA - Rennes), Laboratoire de Génie Civil et de Génie Mécanique (LGCGM), 20 Avenue des Buttes de Coesmes, CS 70839, \\ 35708 Rennes, Cedex 7, France \\ ${ }^{\mathrm{C}}$ Centre de Coopération International en Recherche Agronomique pour le Développement (CIRAD), Unité de recherche Biomass, Wood, Energy, and Bioproducts (BioWooEB), \\ TA B-114/16, 73 rue Jean François Breton, 34398 Montpellier Cedex 5, France
}

\section{H I G H L I G H T S}

- Different surface treatments are applied on oil palm shell (OPS).

- Effects of treated OPS on physico-mechanical properties of concrete are studied.

- Lime treatment increases the mechanical properties of OPS concrete.

- Sodium silicate treatment has not enhanced the bond between cement paste and OPS.

- Prewetting OPS and PVA treatment reduces the shrinkage and thermal conductivity.

\section{A R T I C L E I N F O}

\section{Article history:}

Received 4 May 2017

Received in revised form 15 November 2017

Accepted 29 November 2017

\section{Keywords:}

Biosourced materials

Oil palm shell treatment

Lightweight concrete

Mechanical behaviour

\begin{abstract}
A B S T R A C T
The overuse of natural aggregates for construction causes many environmental problems. In light of their environmental impact, the discussion has increasingly focused on using alternative plant-based materials and processes such as oil palm shells (OPS). However, previous studies show that OPS have a weak adhesion with cement paste, which results in a decrease in the physical and mechanical properties of OPS concretes. One of the solutions for this problem is to carry out a surface treatment on OPS before using them in concrete. This study has examined the influence of five treatments on the physical and mechanical properties of concrete: treatment with lime $(\mathrm{CH})$, sodium silicate (SS), polyvinyl alcohol (PVA), heat treatment $(\mathrm{TH})$ and OPS saturation (SAT). Lime treatment $(\mathrm{CH})$ on OPS showed good improvement in the mechanical properties of concrete, compared to untreated OPS.
\end{abstract}

(c) 2017 Elsevier Ltd. All rights reserved.

\section{Introduction}

Concrete is currently one of the most widely used construction materials. Its wide popularity can be explained by its interesting mechanical properties, its low cost and its extensive range of applications. However, concrete has a negative impact on the environment as it requires a great quantity of natural resources [1]. To eliminate or reduce the negative impact of concrete, several research have been undertaken on the use of by-products and recycled materials for construction. Oil palm shell (OPS) is a by-product

\footnotetext{
* Corresponding author.

E-mail address: adamah.messan@2ie-edu.org (A. Messan).
}

of oil palm production. It consists of small hard particles of different shapes and sizes that can be used as aggregate in concrete.

For years, authors have demonstrated the potential use of OPS for producing structural lightweight concrete. This biomass can be used to obtain concrete with a density ranging from 1725 to $2050 \mathrm{~kg} / \mathrm{m}^{3}$ [1], which corresponds to a $15-25 \%$ reduction in density compared to ordinary concrete. Therefore, using OPS as aggregate leads to a decrease in the loads of concrete structures and consequently a reduction in the cost of construction. Olanipekun et al. [2] found that the cost of construction can be reduced by $42 \%$ when using OPS in concrete.

However, it has been noted that the mechanical properties of the concrete decrease as the concentration of OPS aggregate in concrete increases [2]. Adebayo [3] has reported that the total 
substitution of ordinary aggregates by OPS results in an approximately $50 \%$ decrease in strength. Other studies have proven that OPS-based lightweight concrete has lower mechanical properties than concretes made from other artificial and natural lightweight aggregates [4].

The experimental results in the scientific literature on this subject have shown that the decrease in the OPS concrete strength is linked to the intrinsic properties of OPS and the weakness of the adhesion between OPS and the cement paste. OPS is a porous material with a high water absorption capacity. Its water absorption capacity, which can reach 33\% [5], can be harmful to concrete properties. OPS may absorb a part of the mixing water intended for the cement hydration. Studies [6] have shown that the porosity of the interface between aggregate and cement paste increases with the absorption capacity of aggregate. Treating OPS before using them in concrete has been suggested to prevent this behaviour. By analogy to wood treatments, the literature cites different methods that can be applied on OPS: partial oxidation of the aggregate, waterproofing, treatment with hot water, heat treatment, etc. [7-9] Mannan et al. [8] have observed, for example, that treating OPS in a solution of PVA (polyvinyl alcohol) improved the mechanical performance of the concrete. Yew et al. [9] improved the compressive strength of OPS concrete after heat treatment at $60^{\circ} \mathrm{C}$ for $30 \mathrm{~min}$. It is often difficult to compare the results of published works as the number of variables taken into account by the authors is high. The treatments, the formulation methods (water-tocement ratio, cement concentration, aggregate quantity), the particle size and curing of the concrete vary from one author to another. It is therefore impossible to draw a conclusion as regards which treatment is the best.

The general objective of this study was to examine different OPS treatments, to analyse and compare their influence on the properties of concrete. In our research, parameters such as the formulation method, the processing conditions and the curing conditions of concrete were kept constant. Five different treatments were applied to the OPS, then their effects on the following properties of concrete were studied: apparent density, porosity accessible to water, ultrasound waves speed, compressive and flexural strength and drying shrinkage.

\section{Materials and treatment methods}

\subsection{Materials used}

The cement used was a CEM I 42.5 from the company CIMTOGO produced according to EN 197-1. This cement had a relative density of $3150 \mathrm{~kg} / \mathrm{m}^{3}$, a bulk density of $1060 \mathrm{~kg} / \mathrm{m}^{3}$ and a BET specific area of $2.96 \mathrm{~m}^{2} / \mathrm{g}$.

The OPS used came from "Société Immobilière et Financière de la Côte Africaine" (SIFCA), a palm oil company. Before any treatment and/or utilisation, OPS were washed in water to remove soil and fat residues and air dried. They were then sieved, and only the particles with a diameter less than $8 \mathrm{~mm}$ were retained. OPS particle-size distribution is shown in Fig. 1 . Their relative density was $1340 \mathrm{~kg} / \mathrm{m}^{3}$, their bulk density was $560 \mathrm{~kg} / \mathrm{m}^{3}$ and their 24-h water absorption capacity was $23.3 \%$. These OPS properties were similar to those published in scientific literature. In general, OPS density varies from 1170 to $1370 \mathrm{~kg} / \mathrm{m}^{3}$ and their 24 -h absorption capacity ranges from $21 \%$ to $33 \%$ [10-13].

Sand from a local river was also used. Its particle-size distribution is also shown in Fig. 1. It was a poorly graded sand with a uniformity coefficient $C_{u}$ of 3 and a curvature coefficient $C_{c}$ of 0.9 . The sand equivalent test gave a value of 98 . This indicates that the sand used was very clean and suitable for making concrete of high quality. It had a density of $2680 \mathrm{~kg} / \mathrm{m}^{3}$, a bulk density of $1530 \mathrm{~kg} / \mathrm{m}^{3}$ and a Fineness modulus of 2.90 .

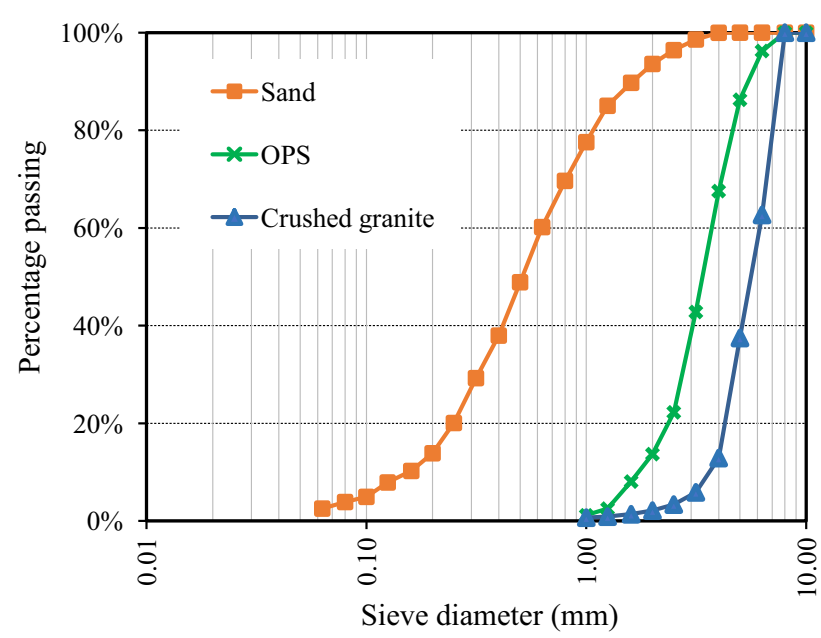

(a)

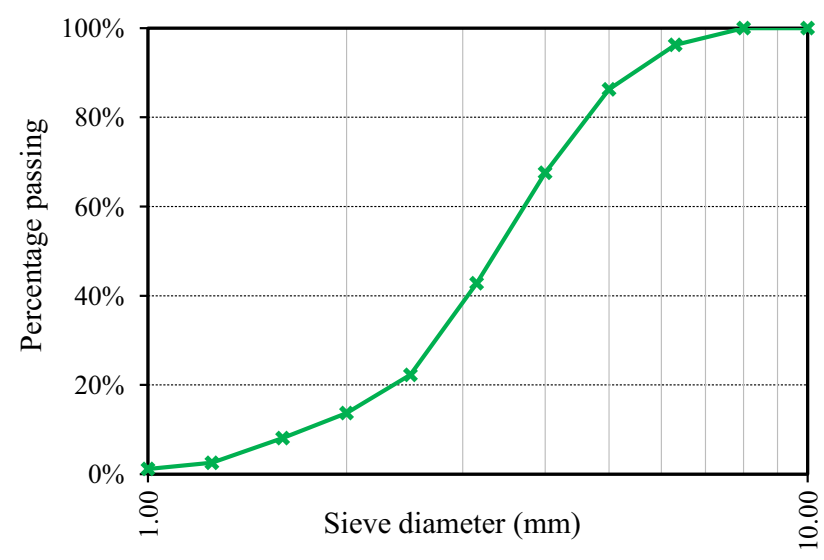

(b)

Fig. 1. Gradation of sand, OPS and crushed granite.

In order to compare the properties of treated OPS concrete to those of ordinary concrete, a granite-based aggregate concrete was prepared. The gravel used had a density of $2660 \mathrm{~kg} / \mathrm{m}^{3}$, a bulk density of $1510 \mathrm{~kg} / \mathrm{m}^{3}$, and a 24-h water absorption capacity of $0.4 \%$. Its particle-size distribution is shown in the Fig. 1.

\subsection{Nature and methods of treatment}

Five different treatments were studied. Their purpose was to reduce the hydrophilic behaviour of OPS or to modify the OPS surface.

A first treatment $(\mathrm{CH})$ consisted of mixing the OPS in a solution of lime $\left(\mathrm{Ca}(\mathrm{OH})_{2}\right)$ for $2 \mathrm{~h}$. The saturated solution was dosed at $40 \mathrm{~g}$ of lime per litre of water. The mix was stirred repeatedly during the entire treatment duration to avoid decantation of lime particles. Authors [14] have observed that lime treatment modifies the surface of the lignocellulosic aggregates used and improves the mechanical strength of their composites. The lime treatment was therefore chosen for these reasons.

A second treatment (SS) comprised the soaking of the OPS for 2 $\mathrm{h}$ in a solution containing $100 \mathrm{~g} / \mathrm{l}$ of sodium silicate. A previous study on lightweight concretes containing wood chips [15] showed that the presence of amorphous silica on wood chips improves bonding with cement paste.

The third treatment (PVA) consisted the covering of the OPS with a solution of $5 \%$ polyvinyl alcohol. This type of solution was used to make each of the particles waterproof [8]. The OPS was 
mixed in the PVA solution for 3 min to ensure it was coated homogeneously. It was then drained and dried at room temperature $\left(30^{\circ} \mathrm{C} \pm 5^{\circ} \mathrm{C}\right)$.

The fourth treatment (TH) was a heat treatment of OPS at $60^{\circ} \mathrm{C}$ for $30 \mathrm{~min}$ in reference to the work of Yew et al. [9]. Heat treatment of OPS can modify its surface roughness, and improves mechanical adhesion between the cement paste and the OPS.

The fifth treatment (SAT) consisted of saturating the OPS with water before using them in concrete. In general, considering the high porosity of lightweight aggregates, which increases their water absorption and retention capacity, several authors recommend wetting lightweight aggregates before using them in concrete. This treatment prevents mixing water intended for hydrating the cement from being absorbed [16-18].

\subsection{Properties of the treated aggregates}

Table 1 shows that the ratio between the masses of aggregates before and after each treatment was always greater than 1 except in the case of heat treatment. These results suggested a deposit of materials after $\mathrm{CH}$, SS and PVA treatments. Heat treatment led to loss of material. After heat treatment, Yew et al. [9] observed that OPS have lower fibre content than untreated OPS. We can conclude that during treatment, heat has removed fibres from OPS. Scanning electron microscope (SEM) observations revealed the presence of deposits on some of the treated OPS (Fig. 2). When analysing the deposit, lime crystals on lime-treated OPS and silica on sodium silicate-treated OPS were found. The treatment with PVA has generated a more homogeneous deposit than the two previous treatments.

The increase/decrease in mass after the different treatments does not necessarily indicate the modification of the granular stacking of the OPS; hence, the bulk density of the aggregates after each treatment was measured. The results obtained are summarised in Table 1 . The density ratios between the $\mathrm{CH}$, SS and TH-treated OPS and the raw OPS were close to 1 . These treatments therefore had little influence on the density of OPS. PVA treatment, on the other hand, gave a density ratio of 0.82 . This suggests that the number of OPS particles treated with PVA in a given volume was lower than the untreated OPS. It can be supposed that the layer of PVA covering the OPS was thicker than the coating of the other treatment, making the OPS coarser. Another reason may be that PVA have affected the friction between the OPS particles, which has influenced the granular stacking.

The influence of treatments on the water absorption capacity and kinetics of OPS was also evaluated. To do this, $150 \mathrm{~g}$ of dry materials from each of the five treated OPS were immersed in water; the absorbed water mass was then measured after 15, 30 , $60,120,240,480$ and $1440 \mathrm{~min}$.

The percentages of absorbed water after $24 \mathrm{~h}(1440 \mathrm{~min})$ are shown in Table 1 . It can be observed that the PVA treatment has reduced slightly the water absorption of OPS. As can be seen in Fig. 2, a thin layer has covered the OPS, and reduced water absorption. Mannan and Ganapathy [8] reached the same conclusion. However, the slight reduction in water absorption suggests that PVA has only partially covered the aggregate. Regarding treatment with lime, the observed lime deposits may have had a similar effect. No visible swelling of the OPS was observed after saturation. This was the case for all the treatments.

OPS treated or not had globally the same trend to absorb water (Fig. 3). After $4 \mathrm{~h}$, the absorption rate was nearly zero for all treatments. However, lime and PVA treated OPS had an absorption rate of $0.5 \% \mathrm{~m}^{-1}$ during the first $30 \mathrm{~min}$, a value twice higher for other treatments.

If we consider the dispersion of the obtained results, the effect of S and TH treatments on OPS absorption can be considered negligible. It can be concluded that only lime and PVA treatments have reduced OPS water absorption capacity.

\subsection{Concrete mixing}

The formulation of OPS concrete differs from that of ordinary concrete, due to the nature of OPS [19]. The formulation method used in this study was based on that of Teo et al. [20]. This method allowed the obtaining of the highest mechanical performance from concrete without cementitious additives, compared to other studies. $550 \mathrm{~kg}$ of cement per $\mathrm{m}^{3}$ of concrete were used with a W/C ratio of 0.4 . The sand to cement and OPS to cement ratios were 1.66 and 0.6 respectively. The formulation of ordinary aggregate concrete $(0 \mathrm{~N})$ was done considering a volume substitution of OPS.

OPS concrete had a slump of approximately $2 \mathrm{~cm}$ with Abrams cone testing. The workability of the concrete was maintained constant for all the formulations. For that, a superplasticiser was used in a proportion varying between $0.7 \%$ and $1.4 \%$ of the cement mass. The concrete was poured and vibrated in three layers in each mould, then the surface was protected by a Polyane film. The specimens were stored in a room at a temperature of $20^{\circ} \mathrm{C} \pm 5$. Specimens were removed from the moulds after $24 \mathrm{~h}$.

\section{Results and discussion}

\subsection{Physical properties of concrete}

\subsubsection{Dry bulk density and porosity accessible to water}

The apparent density and porosity accessible to water of the concretes were evaluated using the gravimetric method (ISO 5017). The test involves saturating the samples with water. The saturated samples are weighed immersed in water and air. Then, the samples are left to dry in an oven and weighed. The results are given in Table 2 .

The OPS concretes obtained from the five treatments had a dry bulk density varying between 1822 and $1867 \mathrm{~kg} / \mathrm{m}^{3}$. Compared to ON concrete, the density of OPS concretes decreased by about $18 \%$. This value being less than $2000 \mathrm{~kg} / \mathrm{m}^{3}$, they are accepted for lightweight concrete structures. All concretes, regardless of treatment

Table 1

Effect of treatment on some properties of OPS.

\begin{tabular}{|c|c|c|c|c|}
\hline Mix code & Treatment of OPS & $\begin{array}{l}\text { Mass ratio before and } \\
\text { after treatment }\end{array}$ & $\begin{array}{l}\text { Apparent density ratio } \\
\text { of bulk OPS after treatment }\end{array}$ & $\begin{array}{l}\text { Water absorption } \\
\text { capacity at } 24 \mathrm{~h}(\%)\end{array}$ \\
\hline $\mathrm{N}$ & No treatment & 1 & 1 & $23.3( \pm 0.4)$ \\
\hline $\mathrm{CH}$ & Lime solution $\left(\mathrm{Ca}(\mathrm{OH})_{2}\right)$ & 1.004 & 1.04 & $20.1( \pm 1.0)$ \\
\hline SS & Sodium silicate solution & 1.012 & 1.06 & $22.4( \pm 0.4)$ \\
\hline PVA & PVA solution & 1.026 & 0.82 & $18.1( \pm 0.6)$ \\
\hline $\mathrm{TH}$ & Heat treatment & 0.948 & 1.02 & $23.9( \pm 0.6)$ \\
\hline SAT & Saturation & 1.23 & - & - \\
\hline
\end{tabular}



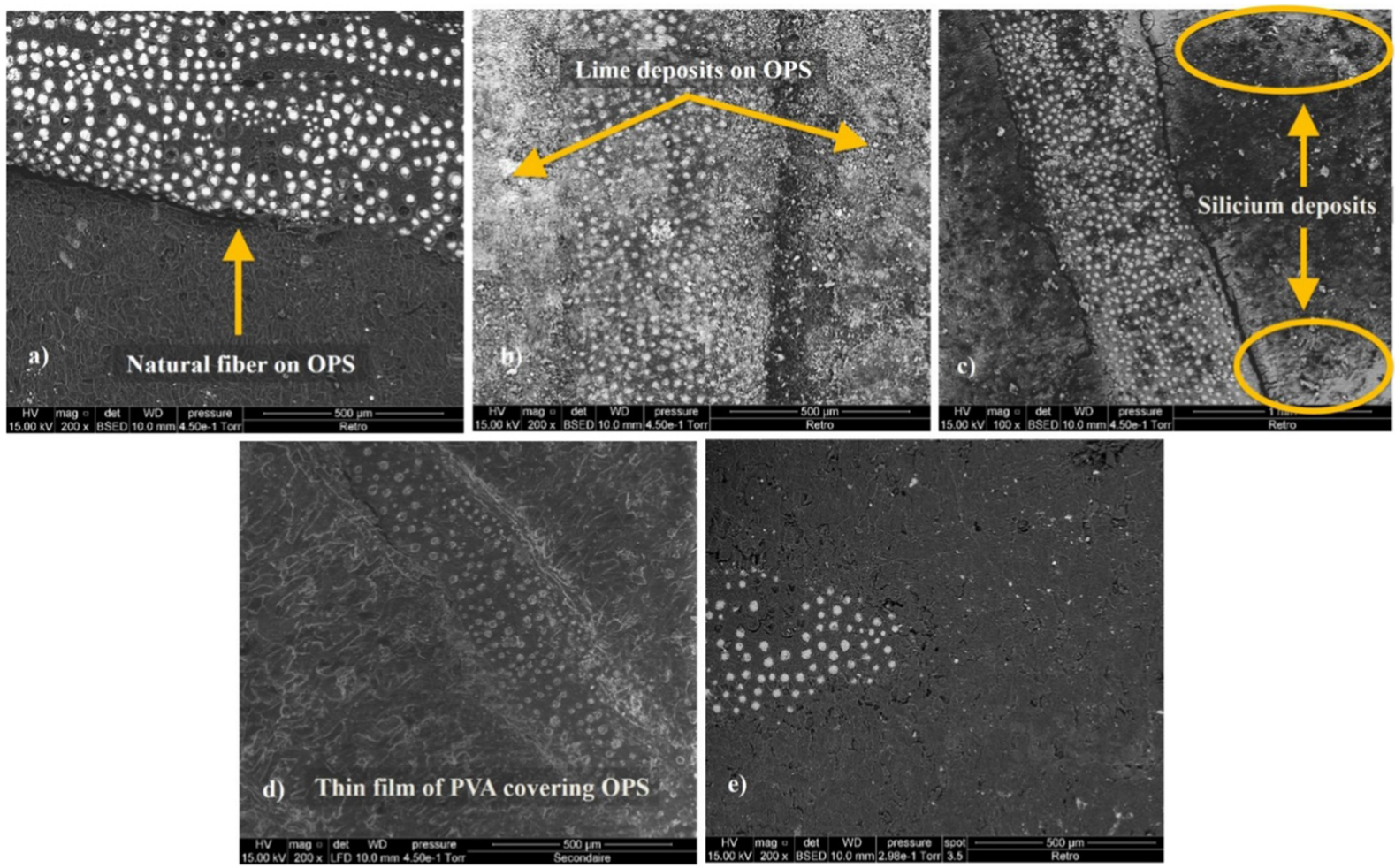

Fig. 2. SEM images of OPS surface before and after different treatments.
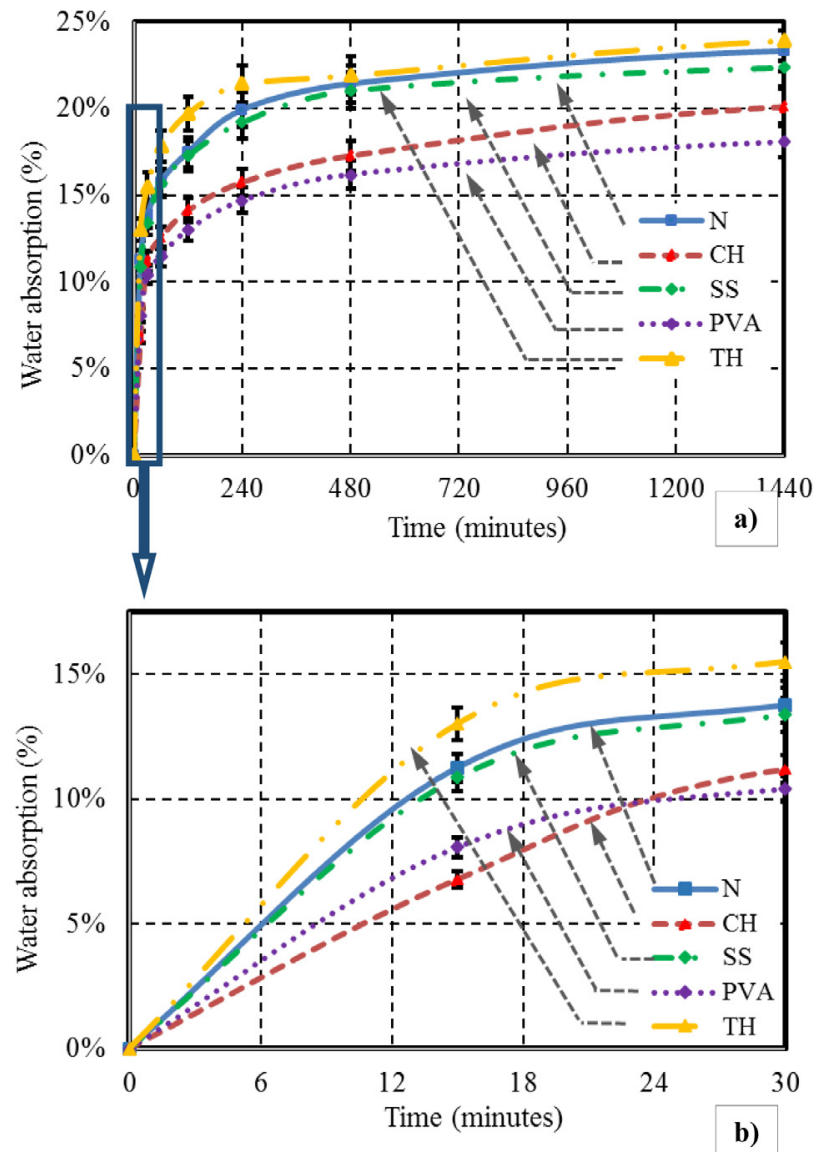

Fig. 3. Water absorption kinetics of OPS aggregates. a) During $1440 \mathrm{~min}$ (24 h). b) During $30 \mathrm{~min}$
Table 2

Some physical properties of the concrete specimens.

\begin{tabular}{llll}
\hline Mix code & $\begin{array}{l}\text { Apparent density } \\
\left(\mathrm{kg} / \mathrm{m}^{3}\right)\end{array}$ & Apparent porosity (\%) & Air content (\%) \\
\hline ON & $2239( \pm 8)$ & $11 \%( \pm 0.4)$ & $3.6 \%( \pm 0.2)$ \\
N & $1839( \pm 6)$ & $17 \%( \pm 0.2)$ & $4.3 \%( \pm 0.3)$ \\
CH & $1847( \pm 10)$ & $17 \%( \pm 0.1)$ & $4.3 \%( \pm 0.1)$ \\
SS & $1859( \pm 17)$ & $17 \%( \pm 0.3)$ & $4.4 \%( \pm 0.2)$ \\
PVA & $1867( \pm 10)$ & $17 \%( \pm 0.2)$ & $4.5 \%( \pm 0.2)$ \\
TH & $1849( \pm 7)$ & $17 \%( \pm 0.2)$ & $4.2 \%( \pm 0.1)$ \\
SAT & $1822( \pm 23)$ & $18 \%( \pm 0.1)$ & $5.7 \%( \pm 0.3)$ \\
\hline
\end{tabular}

had densities neighbouring it. The different treatments therefore had no real influence on the density of concrete. The nonparametric Kruskal-Wallis test [21] was applied to the density results of the six OPS concretes to see whether or not the differences were significant (Table 3). This type of test was chosen because the samples are of a small size. The $\mathrm{p}$ - value calculated by the asymptotic method gave a value of 0.08 , which was greater than the significance threshold $\alpha$ considered $(\alpha=0.01)$. The null hypothesis $\mathrm{H}_{0}$ which states that the six samples come from the same population therefore could not be rejected. Moreover, the analysis of samples from the population taken two-by-two showed no significant difference. It can therefore be concluded that the treatments had no influence on the density of the concrete.

Table 3

Kruskal Wallis test results.

\begin{tabular}{ll} 
K (Observed value) & 9.795 \\
K (Critical value) & 15.086 \\
Degrees of Freedom (DF) & 5 \\
P-value (bilateral) & 0.081 \\
Significance threshold $(\alpha)$ & 0.01 \\
\hline
\end{tabular}


Concerning the porosity accessible to water (Table 2), all the concretes had a porosity of $17 \%$ except the SAT concrete, which corresponds to an increase in porosity of $35 \%$ compared to ordinary aggregate concrete. Furthermore, the amount of air entrained during the mixing of the fresh concrete was measured using a mortar aerometer according to the standard NF EN 12,350-7. Test results are also shown in Table 2. Values indicated 3.6\% for $0 \mathrm{~N}$ concrete and $4.2-5.3 \%$ for OPS concrete. As can be seen in Fig. 1, OPS had more fine particles than granite aggregate. However, the finer the aggregate, the higher the occluded air. Moreover, OPS are particles of irregular shapes that limit the compaction of concrete, which leads to an increase in the volume of occluded air in concrete. Therefore, this can justify the results observed. The volume of occluded air for SAT concrete was more significant compared to other treatments, which explains the slight increase in the porosity of SAT concrete.

\subsubsection{Propagation of ultrasonic waves}

The propagation characteristics of ultrasonic waves in a material can be used to evaluate some of its properties. The propagation speed of a wave, for example, gives an idea of the microstructure of the material and its state of damage. The test was conducting by passing a pulse of ultrasonic waves through the sample to be tested and measuring the time taken by pulse to get through the sample. An ultrasonic testing equipment, the PUNDIT LAB was used according to ASTM C597. To carry out this test, the surfaces of the samples were scrapped in order to improve the contact with the acoustic device.

Fig. 4 shows the average of ultrasonic wave speeds obtained for 3 samples per formulation. This speed varies slightly from one treatment to another.

The highest propagation speed, $3509 \mathrm{~m} / \mathrm{s}$, was obtained with the lime-treated sample. The lowest propagation speed obtained was for the SAT treatment, $3352 \mathrm{~m} / \mathrm{s}$ undoubtedly linked to the increased porosity due to the prewetting of the OPS. Indeed, ultrasound waves are more attenuated when travelling in a vacuum of the cement matrix than in solid materials. The resulting ultrasonic wave speed of conventional concrete was $4207 \mathrm{~m} / \mathrm{s}$. This value is about $23 \%$ greater than the propagation speed in OPS concretes regardless of treatment. It is thus possible to assume that OPS, this organic and porous material, strongly have attenuated the propagation of the ultrasonic waves. Benazzouk et al. [22] arrived at this same conclusion, having obtained a propagation speed in their rubbery material of $175 \mathrm{~m} / \mathrm{s}$ against $3600 \mathrm{~m} / \mathrm{s}$ for the cementitious matrix.

\subsubsection{Thermal conductivity, specific capacity and thermal diffusivity} test

The treatments produced different types of changes to the OPS and the concrete. Their influence on the thermal behaviour of the

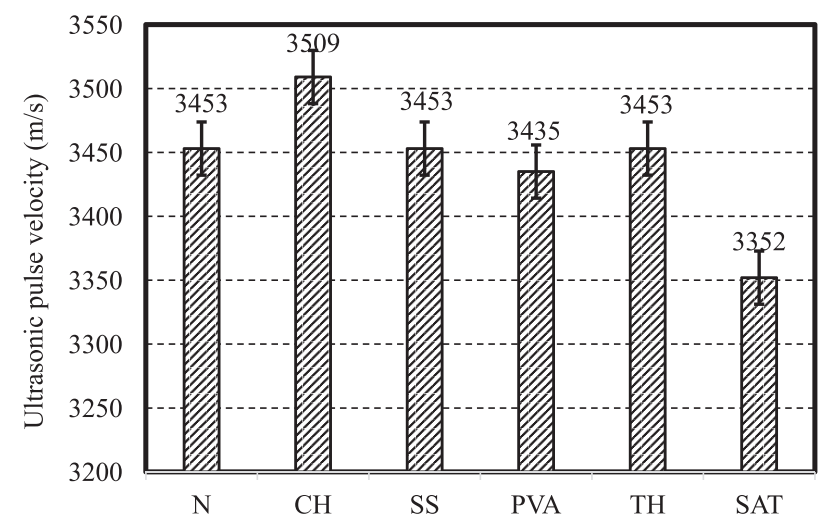

Fig. 4. Ultrasonic wave velocity of CNP concrete. concrete has thus been studied. The thermal properties (thermal conductivity, specific heat and thermal diffusivity) of the different formulations were determined using a Hot Disk TPS 1500 device (Fig. 5). Heat is passed through a probe between the flat surfaces of two dry samples ( $40 \mathrm{~mm} \times 20 \mathrm{~mm}$ cylinders) of the concrete studied. The heat source is a double spiral insulated in nickel, which is used both for transient heating and accurate temperature readings. The samples were dried at $60^{\circ} \mathrm{C}$, until a constant mass was obtained (variation between 2 weightings separated by $24 \mathrm{~h}$ $<0.1 \%$ ). The thermal conductivity, specific heat and thermal diffusivity values are given in Table 4 and Fig. 6.

The OPS concretes studied had a thermal conductivity between 1 and $1.6 \mathrm{~W} / \mathrm{mK}$. These values were lower than ordinary concrete, which was of the order of $2.1 \mathrm{~W} / \mathrm{mK}$. These low values can be attributed to, among other things, the low thermal conductivity of OPS compared to conventional aggregates [11]. OPS have improved the thermal properties of the material by increasing its insulating characteristics. These characteristics are especially interesting for applications in high-temperature regions because they will contribute to improved thermal comfort in houses. Concerning the influence of the different treatments, it can be observed in Fig. 6a that the $\mathrm{CH}$, SS and $\mathrm{TH}$ treatments do not have any real influence on the heat conductivity of OPS concrete. SAT OPS concrete, whose porosity was the highest, exhibited the 2nd lowest value for thermal conductivity $(1.09 \mathrm{~W} / \mathrm{mK})$. This decrease in thermal conductivity compared to N OPS concrete is linked to the additional porosity created by the OPS prewetting. Indeed, the thermal conductivity of air in dry pores is much lower than aggregates or cement paste. Thus, the more porous a composite, the lower its thermal conductivity [23]. PVA OPS concrete exhibited the lowest thermal conductivity, even though the treatment did not change the porosity of the OPS. In this case, the PVA film that coats the OPS after the treatment has lowered the equivalent thermal conductivity of treated OPS compared to untreated OPS.

The specific heat and volumetric heat capacity are used to measure the capacity of composites to resist changes in temperature. As opposed to thermal conductivity, the higher the value of the specific heat, the more the material can retain heat and thus resist variations in temperature. The results of Table 4 indicate for $0 \mathrm{~N}$ concrete a specific heat of $1.89 \mathrm{MJ} / \mathrm{m}^{3} \mathrm{~K}$. Untreated OPS concrete (N) had a specific heat approximately $25 \%$ greater than this amount. It therefore resists changes in temperature more effectively than ordinary concrete. Fig. $6 \mathrm{~b}$ shows the influence of OPS treatment on the specific heat of concrete. We have observed no influence of $\mathrm{CH}$ and SS treatments on the thermal capacity of OPS concrete. On the other hand, PVA, TH and SAT OPS concretes exhibited a great sensitivity to variations in temperature. A reduction of $43 \%, 24 \%$ and $21 \%$ for the PVA, TH and SAT concretes respectively was noted, compared to the N OPS concrete. These values remain in the same order of magnitude as those of ordinary concrete.

Thermal conductivity and specific heat are also used to define the capacity of a material to transmit heat from one point to another. This capacity, called thermal diffusivity, is defined as described in (1):

$a=\lambda / C_{p}$

where $\lambda$ is the thermal conductivity of the material and $C_{p}$, the volumetric heat capacity.

Fig. $6 \mathrm{c}$ shows the thermal diffusivity values obtained for the tested composites. They vary between 0.59 and $0.79 \mathrm{~mm}^{2} / \mathrm{s}$. All the thermal diffusivity values are less than $1.13 \mathrm{~m}^{2} / \mathrm{s}$ of $0 \mathrm{~N}$ ordinary concrete. It can thus be observed that despite its lower thermal conductivity, PVA concrete has one of the highest thermal diffusivity coefficients, and so is TH concrete. This result is related to the lower specific heat value obtained for these concretes. 

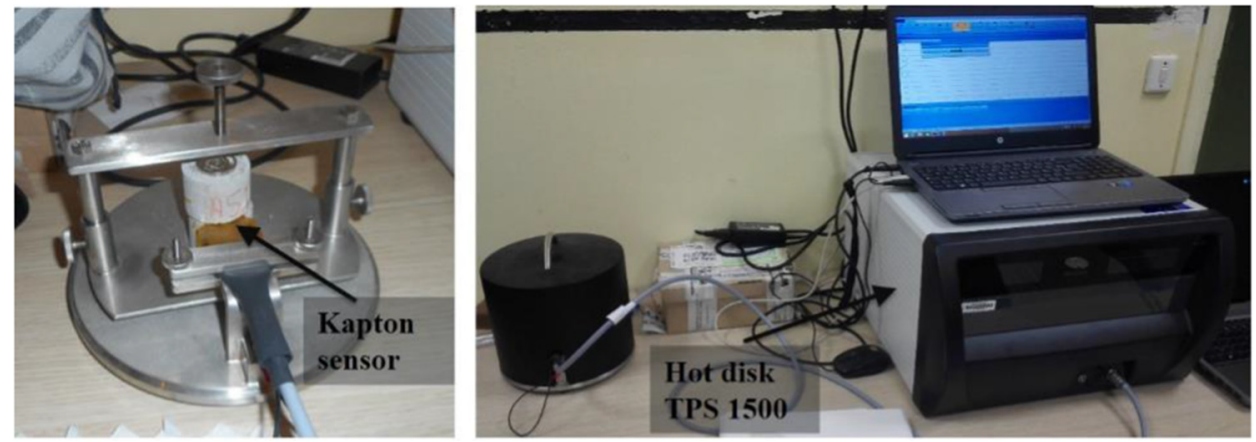

Fig. 5. Hot disk thermal constants analyser.

Table 4

Thermal properties of concrete samples with and without OPS.

\begin{tabular}{llll}
\hline Mix code & $\begin{array}{l}\text { Thermal conductivity } \\
(\mathrm{W} / \mathrm{mK})\end{array}$ & $\begin{array}{l}\text { Specific heat } \\
\left(\mathrm{MJ} / \mathrm{m}^{3} \mathrm{~K}\right)\end{array}$ & $\begin{array}{l}\text { Thermal diffusivity } \\
\left(\mathrm{mm}^{2} / \mathrm{s}\right)\end{array}$ \\
\hline ON & $2.13( \pm 0.04)$ & $1.89( \pm 0.16)$ & $1.13( \pm 0.08)$ \\
$\mathrm{N}$ & $1.54( \pm 0.03)$ & $2.35( \pm 0.05)$ & $0.66( \pm 0.01)$ \\
\hline
\end{tabular}

\subsection{Mechanical properties of the concrete}

To qualify the mechanical behaviour of the OPS concretes studied, three common mechanical properties were studied: compressive strength, flexural strength and the static modulus of elasticity.

The compressive strength of composites was measured on cylindrical test specimens of $50 \mathrm{~mm}$ in diameter and $100 \mathrm{~mm}$ in height. The tests were carried out on the samples after $7,14,28$, 56 and 90 days of maturity. For each compressive strength test, three samples were tested on a hydraulic press with a maximum capacity of $200 \mathrm{kN}$ at a constant speed of $0.25 \mathrm{~mm} / \mathrm{min}$. The values retained for each formulation are an average of the values of the 3 tested samples.

The 3-point bending test was performed to measure the flexural strength of each formulation. A loading rate of $5 \mathrm{~mm} / \mathrm{min}$ was used for this test. The deflection for each specimen was recorded during the test.

\subsubsection{Flexural and compressive strengths}

The compressive strength of untreated OPS concrete at 28 days of maturity was $23.7 \mathrm{MPa}$, or a decrease of $43 \%$ compared to $0 \mathrm{~N}$ concretes. Three of the treatments on OPS showed improvement in the compressive strength after 28 days of OPS concrete compared to untreated OPS concrete (Table 5). There was an $8 \%, 5 \%$ and 6\% improvement for the $\mathrm{CH}$, SS and $\mathrm{TH}$ treatments respectively compared to $\mathrm{N}$ concrete, which correspond to a decrease of $39 \%$, $41 \%$ and $40 \%$ compared to $0 \mathrm{~N}$ ordinary concrete. This increase in the compressive strength after treatment may be due to an improvement in adherence between the treated OPS and the cement paste. The PVA treatment did not result in any real improvement to the compressive strength of OPS concrete. However, Mannan et al. [8] in their study obtained a $20 \%$ increase in compressive strength when a PVA treatment is applied to the OPS.

It is recommended to prewet aggregates before using them in concrete, specifically when using lightweight aggregates. Yet, too much prewetting could lead to a fall in the mechanical performance of lightweight concrete. Cortas et al. studied the effect of water concentration of natural aggregates on the behaviour of
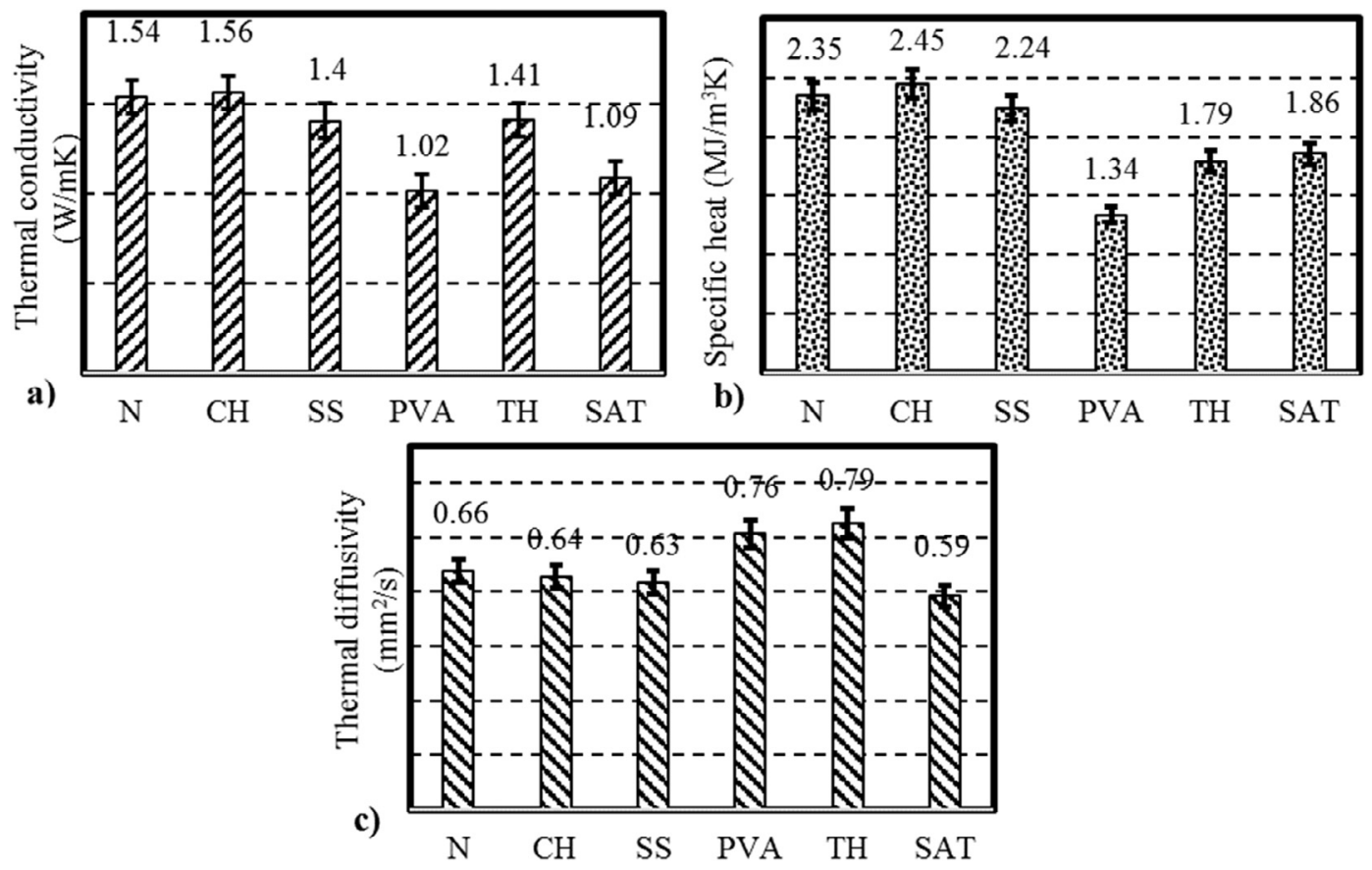

Fig. 6. Thermal properties of concrete. a) Thermal conductivity. b) Specific heat. c) Thermal diffusivity. 
Table 5

Mechanical properties of concrete specimens.

\begin{tabular}{lll}
\hline Mix code & Compressive strength $(\mathrm{MPa})$ & Flexural strength $(\mathrm{MPa})$ \\
\hline ON & $41.8( \pm 1.8)$ & $6.4( \pm 0.5)$ \\
N & $23.7( \pm 1.0)$ & $4.7( \pm 0.4)$ \\
CH & $25.5( \pm 0.8)$ & $5.0( \pm 0.5)$ \\
SS & $24.7( \pm 0.8)$ & $4.4( \pm 0.1)$ \\
PVA & $21.9( \pm 1.2)$ & $4.1( \pm 0.1)$ \\
TH & $25.1( \pm 0.5)$ & $4.9( \pm 0.3)$ \\
SAT & $20.5( \pm 1.5)$ & $4.0( \pm 0.2)$ \\
\hline
\end{tabular}

lightweight concrete. They observed a decrease in the compressive and the tensile strengths when they replaced dry aggregate with wet aggregate. This loss of mechanical performance is due to an area of increased porosity at the interface between the aggregate and the cementitious matrix [24]. It also explains the weakness of SAT OPS concrete compared to other composites tested with a decrease in strength close to $13 \%$ compared to $\mathrm{N}$ concrete.

The evolution of compressive strength with time for the different concretes is shown in Fig. 7. After 7 days, the compressive strength of the N OPS concrete corresponded to $92 \%$ of its value after 28 days and changes very little from thereon. This behaviour was also observed for concretes with a large cement concentration, like in this study. The different treatments had no visible influence on the evolution of the compressive strength. The compressive strength over time of OPS concretes is influenced by the quality of the cement paste and aggregate. However, the evolution of concrete strength in time also depends on the quality of the interface between the aggregate and the cementitious matrix. Many authors agree that the compressive strength of the OPS concrete is severely limited by the bond between the OPS and the cementitious matrix $[13,25,26]$. The breakage of the concrete comes from this weak bond. In this event, neither the strength of the aggregate nor the cementitious matrix contributes to the strength of the concrete, which explains the weak change in strength of concretes after 28 days.

All the concretes formulated had a flexural strength varying between 4.0 and 5.0 MPa. The Kruskal-Wallis test was applied to the results of the flexural test. A p-value of 0.044 was obtained, which is greater than the significance level of 0.01 considered. Hypothesis $\mathrm{H}_{0}$ therefore cannot be rejected. It can be concluded from this analysis that there is no significant difference between the flexural strength of the different concretes mixed. The OPS treatments thus had no effect on the flexural strength of the concrete.

\subsubsection{Static modulus of elasticity}

The modulus of elasticity is a very important parameter when dimensioning structural elements composed of reinforced

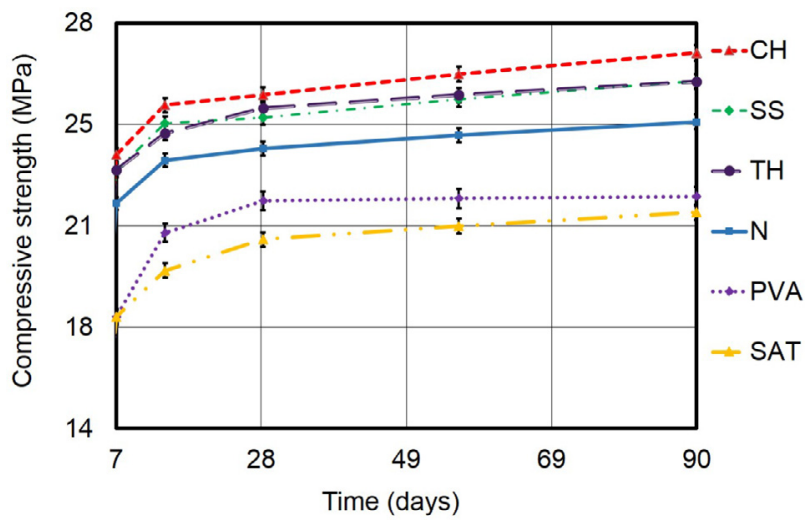

Fig. 7. Evolution of the compressive strength OPS concrete after treatment. concrete. The modulus of elasticity has been deduced from the deformation measurements made during the uniaxial compression test. It corresponds to the slope of the stress-strain curve in its linear part. The moduli of elasticity obtained for the various OPS concretes are shown in Fig. 8. The average modulus of elasticity of the control concrete $(0 \mathrm{~N})$ was in the order of $21.6 \mathrm{GPa}$. The modulus of elasticity of N OPS concrete was equivalent to around $1 / 3$ of this value. Mannan et al. [13] obtained a similar result with an elastic modulus varying between 7.0 and $7.6 \mathrm{GPa}$. This decrease in concrete modulus of elasticity is due to the low rigidity of OPS on the one hand, but also to the weak adherence between the OPS and the cement paste on the other hand.

Among all the OPS treatments, lime treatment $(\mathrm{CH})$ exhibited a significant influence on the elastic modulus of the concrete. Indeed, the $\mathrm{CH}$ treatment gave a modulus of elasticity of $12.1 \mathrm{GPa}$, which corresponds to a more than $64 \%$ increase in the elastic modulus compared to $\mathrm{N}$ concrete. In principle, the modulus of elasticity is strongly influenced by the aggregate-cement paste adhesion [27]. At equal density and porosity accessible to water, the results of the elastic modulus obtained for $\mathrm{CH}$ OPS concrete supports the hypothesis that $\mathrm{CH}$ treatment has improved the adherence of OPS with the cement paste.

\subsubsection{Drying shrinkage}

Drying shrinkage was measured on prismatic specimens of dimensions $40 \mathrm{~mm} \times 40 \mathrm{~mm} \times 160 \mathrm{~mm}$ at the end of which studs were embedded (Fig. 9). The variation in length of the specimen was measured using a retractometer equipped with balls that are positioned in contact with the studs. The specimens were kept in a controlled atmosphere room, according to standard NF P15-433. Figs. 10 and 11 show the change over time of the free shrinkage and the loss of mass of the samples.

The OPS concretes studied had a shrinkage deformation varying between 1325 and $2065 \mu \mathrm{m} / \mathrm{m}$ after 90 days. These deformations correspond on average to twice the shrinkage of $0 \mathrm{~N}$ concrete. Other studies obtained similar results in the first months of OPS concrete maturity, with a drying shrinkage five times higher than normal concrete [1]. They have attributed this shrinkage increase to the loss of water during concrete drying $[1,28]$. Mass losses alone cannot explain the magnitude of drying shrinkage observed for the different composites. Indeed, although the shrinkages were more significant for OPS concretes, the results of Fig. 11 show that mass losses are nearly identical for both OPS concrete (except for SAT concrete) and $\mathrm{ON}$ concrete. The magnitude of drying shrinkage can be defined as a function of the nature of the aggregate, their concentration in the mix and the shrinkage of the cementitious matrix [29]. Aggregate that has a low modulus of elasticity, for example, does not resist deformations of the cement paste, hence

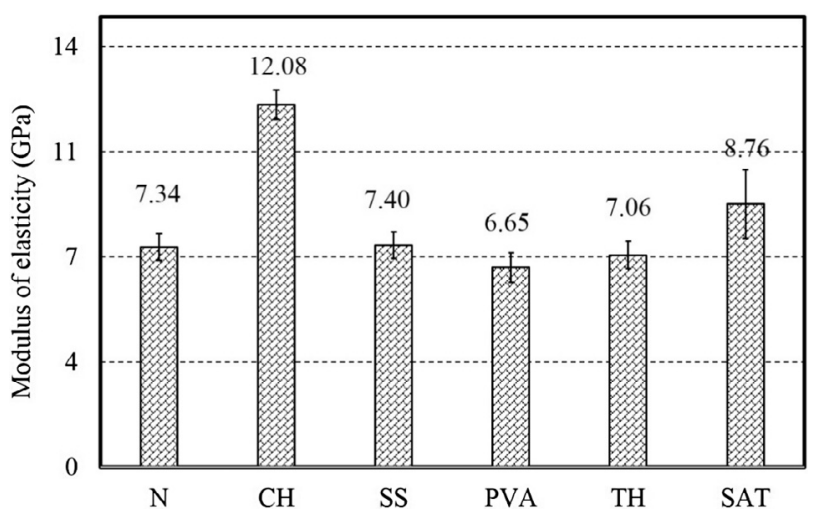

Fig. 8. Modulus of elasticity of CNP concrete specimens. 


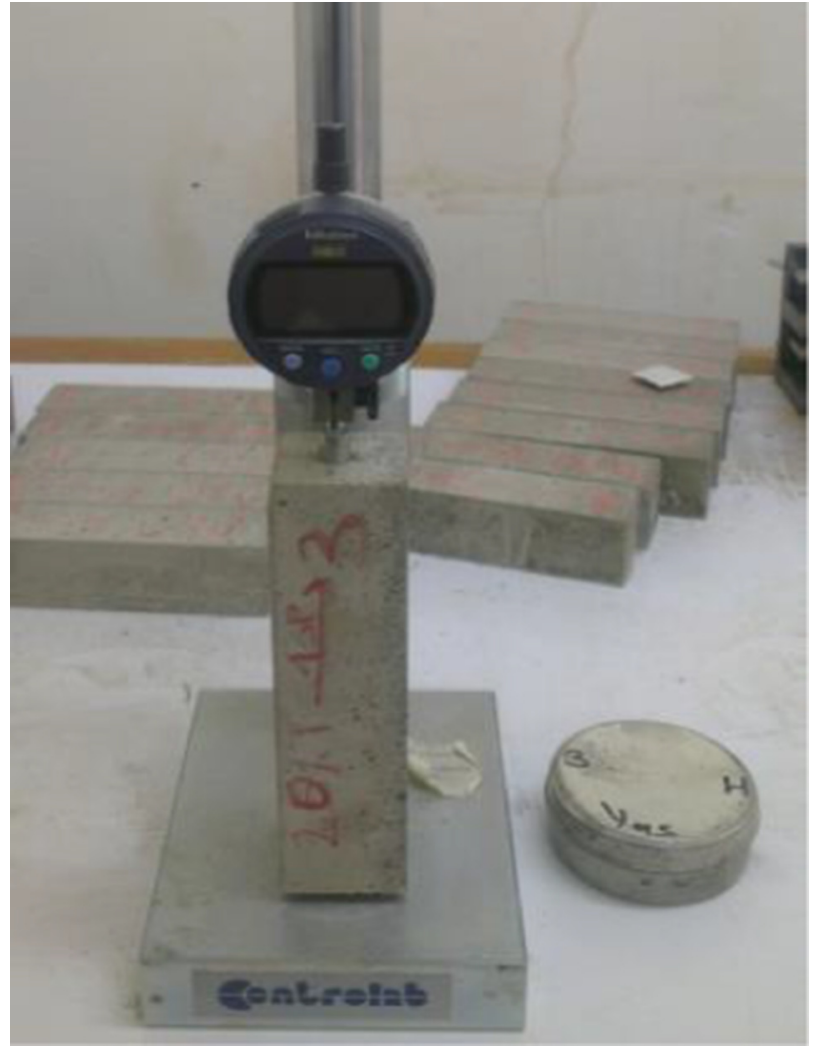

Fig. 9. Shrinkage measurements apparatus.

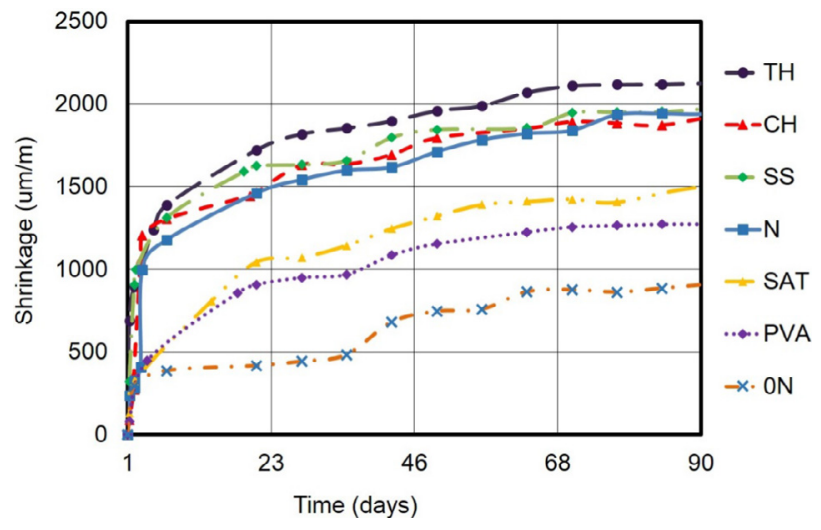

Fig. 10. Evolution of drying shrinkage with time.

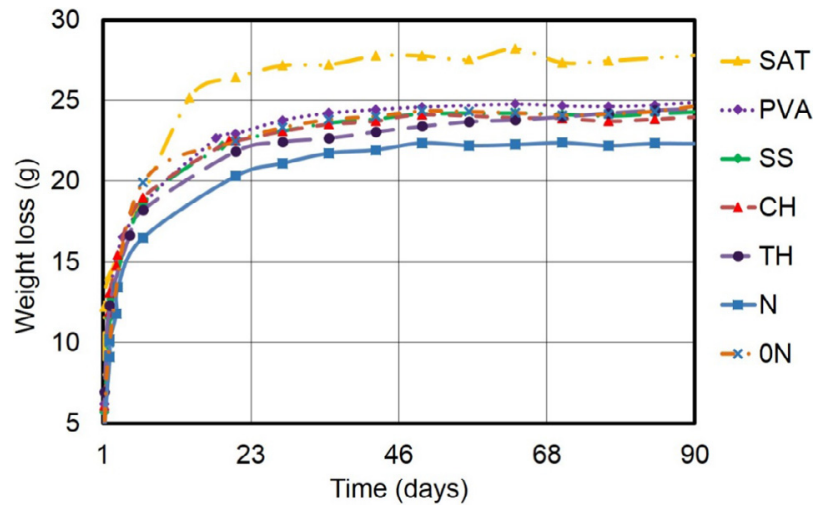

Fig. 11. Weight loss during specimens drying. shrinkage deformations rise [30]. The difference in rigidity between the OPS and ordinary aggregate could therefore explain the results obtained. The largest loss of water observed for the SAT OPS concrete can be explained by its occluded air content and porosity accessible to water, which are higher than the other composites. Thus, the water leaves more quickly and in greater quantities through the system of pores.

Additionally, Fig. 10 shows that the SAT and PVA OPS concretes have the lowest shrinkage deformations. Shrinkage is also influenced by the capillary pressure. According to Laplace, this capillary pressure depends on the pores size and the internal water contact angle $\theta(2)$.

$\Delta_{p}=\frac{2 \gamma}{r} \cos \theta$

where $\Delta \mathrm{p}$ is the pressure difference across the two fluids interface (air and water), $\gamma$ is the surface tension and $r$ the radius of the meniscus formed at the interface between the two fluids.

From (2), it can be assumed that the bigger the radius of the pores, the lower the capillary pressure and the shrinkage. It can then be concluded that PVA and SAT concrete has bigger pores than the untreated OPS concrete. Therefore, the corresponding concrete shrinkage is reduced. Furthermore, the amount of water available in OPS SAT can influence the internal humidity of concrete. Considering that drying shrinkage depends on the loss of water from the cement paste, this extra water coming from prewetted OPS in concrete during drying can increase the angle of the internal water with the walls of the pores. In this case, considering (2), the capillary pressure is lowered and so is the shrinkage. Different authors have also found that saturated aggregate reduced concrete shrinkage $[26,31-33]$.

\section{Conclusion}

The purpose of this study was to examine the influence of different treatments on the properties of OPS and the behaviour of concretes made with the treated OPS aggregate. Five treatments were investigated: treatment with lime $(\mathrm{CH})$, sodium silicate (SS), polyvinyl alcohol (PVA), heat treatment (TH) and OPS prewetting (SAT). The analysis of OPS after $\mathrm{CH}, \mathrm{SS}$ and PVA treatments revealed a deposit of lime, silica and PVA, respectively. The TH treatment resulted in a loss of OPS mass. Taking into account this variation in the mass of the aggregates, the OPS absorption capacity results showed a slight reduction only for the $\mathrm{CH}$ and PVA treatments.

The application of the non-parametric Kruskal-Wallis test to the results obtained leads to the conclusion that the different treatments have no influence on the porosity accessible to water, the bulk density and the flexural strength of the OPS concrete. Among the treatments used, the treatment with lime demonstrated promising results over all. These results showed an increase in the propagation speed of ultrasonic waves compared to untreated OPS concrete. An improvement of around $10 \%$ in the compressive strength after 28 days was also observed; this strength continues to change over time. Moreover, the CH OPS concrete had an elastic modulus of $12.1 \mathrm{GPa}$ compared to only 7.1-8.8 GPa for the other concretes. This indicates the ability of lime treatment to improve the adherence of OPS with cementitious matrix. Considering thermal properties and shrinking, the $\mathrm{CH}$ treatment did not result in any notable changes.

The SS and TH OPS concrete did not exhibit any major changes compared to N OPS concrete. As expected, the PVA treatment has slightly reduced the absorption capacity of OPS, but it has not resulted in any real improvement in the mechanical properties of the concrete compared to $\mathrm{N}$ concrete. However, concrete with 
OPS treated PVA showed a decrease in thermal conductivity and drying shrinkage.

Prewetting the aggregate is suggested by various authors for lightweight concretes. The results obtained in this study reveal a decrease in the mechanical properties of concrete made from saturated OPS. The OPS prewetting water quantity should thus be determined precisely, so as to not interfere with the mixing water and increase the water-cement $(\mathrm{W} / \mathrm{C})$ ratio of the concrete. Nevertheless, the SAT OPS concrete showed the best results in terms of thermal conductivity and reducing shrinkage.

\section{References}

[1] U.J. Alengaram, B.A.A. Muhit, M.Z. Bin Jumaat, Utilization of oil palm kernel shell as lightweight aggregate in concrete - a review, Constr. Build. Mater. 38 (2013) 161-172, https://doi.org/10.1016/j.conbuildmat.2012.08.026.

[2] E.A. Olanipekun, K.O. Olusola, O. Ata, A comparative study of concrete properties using coconut shell and palm kernel shell as coarse aggregates, Build. Environ. 41 (2006) 297-301, https://doi.org/10.1016/j. buildenv.2005.01.029.

[3] O. Adebayo, Assessment of palm kernel shell as aggregate in concrete and laterite blocks, J. Eng. Stud. Res. 18 (2012).

[4] P. Shafigh, H.B. Mahmud, M.Z. Jumaat, M. Zargar, Agricultural wastes as aggregate in concrete mixtures - a review, Constr. Build. Mater. 53 (2014) 110-117, https://doi.org/10.1016/j.conbuildmat.2013.11.074.

[5] D.C. Teo, M.A. Mannan, J.V. Kurian, Flexural behaviour of reinforced lightweight concrete beams made with oil palm shell (OPS), J. Adv. Concr. Technol. 4 (2006) 459.

[6] T.Y. Lo, H.Z. Cui, W.C. Tang, W.M. Leung, The effect of aggregate absorption on pore area at interfacial zone of lightweight concrete, Constr. Build. Mater. 22 (2008) 623-628.

[7] M.A. Mannan, C. Ganapathy, Concrete from an agricultural waste-oil palm shell (OPS), Build. Environ. 441-448 (2004).

[8] M.A. Mannan, J. Alexander, C. Ganapathy, D.C.L. Teo, Quality improvement of oil palm shell (OPS) as coarse aggregate in lightweight concrete, Build. Environ. 41 (2006) 1239-1242, https://doi.org/10.1016/j.buildenv.2005.05.018.

[9] M.K. Yew, H.B. Mahmud, B.C. Ang, M.C. Yew, Effects of heat treatment on oil palm shell coarse aggregates for high strength lightweight concrete, Mater. Des. 54 (2014) 702-707, https://doi.org/10.1016/j.matdes.2013.08.096.

[10] F.O. Okafor, Palm kernel shell as a lightweight aggregate for concrete, Cem. Concr. Res. 18 (1988) 901-910, https://doi.org/10.1016/0008-8846(88)900269.

[11] D.C. Okpala, Palm kernel shell as a lightweight aggregate in concrete, Build. Environ. 25 (1990) 291-296, https://doi.org/10.1016/0360-1323(90)90002-9.

[12] A.A. Abdullah, Palm Oil Shell Aggregate for Lightweight Concrete-10, Waste Mater. Used Concr. Manuf., Noyes Publ, 1997.

[13] M.A. Mannan, C. Ganapathy, Engineering properties of concrete with oil palm shell as coarse aggregate, Constr. Build. Mater. 16 (2002) 29-34, https://doi. org/10.1016/S0950-0618(01)00030-7.

[14] V. Nozahic S. Amziane Influence de différents traitements sur l'interface entre des particules lignocellulosiques et un liant minéral Association Universitaire de Génie Civil 201111

[15] S. Tamba, L.M. Voumbo, A. Wereme, S. Gaye, G. Sissoko, Durabilité des bétons légers à base de copeaux de bois, J. Sci. 7 (2007) 67-72.
[16] M.A. Mannan, C. Ganapathy, Mix design for oil palm shell concrete, Cem. Concr. Res. 31 (2001) 1323-1325, https://doi.org/10.1016/S0008-8846(01) 00585-3.

[17] K.H. Mo, U.J. Alengaram, M.Z. Jumaat, Experimental investigation on the properties of lightweight concrete containing waste oil palm shell aggregate Procedia Eng. 125 (2015) 587-593, https://doi.org/10.1016/j. proeng.2015.11.065.

[18] D. Shen, J. Jiang, J. Shen, P. Yao, G. Jiang, Influence of prewetted lightweight aggregates on the behavior and cracking potential of internally cured concrete at an early age, Constr. Build. Mater. 99 (2015) 260-271, https://doi.org/ 10.1016/j.conbuildmat.2015.08.093.

[19] P. Shafigh, M.Z. Jumaat, H. Mahmud, Mix design and mechanical properties of oil palm shell lightweight aggregate concrete: a review, Int. J. Phys. Sci. 5 (2010) 2127-2134.

[20] D.C.L. Teo, M.A. Mannan, V.J. Kurian, C. Ganapathy, Lightweight concrete made from oil palm shell (OPS): structural bond and durability properties, Build. Environ. 42 (2007) 2614-2621.

[21] E. Theodorsson-Norheim, Kruskal-Wallis test: BASIC computer program to perform nonparametric one-way analysis of variance and multiple comparisons on ranks of several independent samples, Comput. Methods Programs Biomed. 23 (1986) 57-62, https://doi.org/10.1016/0169-2607(86) 90081-7.

[22] A. Benazzouk, O. Douzane, T. Langlet, K. Mezreb, F. Labbani, J.-M. Roucoult, Effet des granulats de caoutchouc sur les propriétés d'un mortier de ciment, XIV Colloq. Natl. Rech. Dans IUT CNRIUT 2008, 2008.

[23] H. Oktay, R. Yumrutas, A Akpolat, Mechanical and thermophysical properties of lightweight aggregate concretes, Constr. Build. Mater. 96 (2015) 217-225, https://doi.org/10.1016/j.conbuildmat.2015.08.015.

[24] T.D. Nguyen, Étude de la zone d'interphase «granulats calcaires poreux-pâte de ciment»: Influence des propriétés physico-mécaniques des granulats; Conséquence sur les propriétés mécaniques du mortier, Saint-Etienne, EMSE, 2013.

[25] D.C.L. Teo, M.A. Mannan, V.J. Kurian, Structural concrete using oil palm shel (OPS) as lightweight aggregate, Turk. J. Eng. Environ. Sci. 30 (2009) 251-257.

[26] M. Aslam, P. Shafigh, M.Z. Jumaat, Oil-palm by-products as lightweight aggregate in concrete mixture: a review, J. Clean. Prod. 126 (2016) 56-73, https://doi.org/10.1016/j.jclepro.2016.03.100.

[27] M. Arnould, M. Virlogeux, M. Albenque, G. Cougny, R. Bertrandy, P. Gaudon, R. Struillou, G. Coquillat, C. Lejeune, R. Lesage, et al., Granulats et bétons légers, 1986.

[28] M. Aslam, P. Shafigh, M.Z. Jumaat, Drying shrinkage behaviour of structural lightweight aggregate concrete containing blended oil palm bio-products, J. Clean. Prod. 127 (2016) 183-194, https://doi.org/10.1016/j. jclepro.2016.03.165.

[29] P. Monteiro, Concrete: Microstructure, Properties, and Materials, McGraw-Hill Publishing, 2006.

[30] A.M. Neville, Propriétés des bétons, Eyrolles, Paris, France, 2000.

[31] H.B. Basri, M.A. Mannan, M.F.M. Zain, Concrete using waste oil palm shells as aggregate, Cem. Concr. Res. 29 (1999) 619-622, https://doi.org/10.1016/ S0008-8846(98)00233-6.

[32] R. Henkensiefken, D. Bentz, T. Nantung, J. Weiss, Volume change and cracking in internally cured mixtures made with saturated lightweight aggregate under sealed and unsealed conditions, Cem. Concr. Compos. 31 (2009) 427-437, https://doi.org/10.1016/j.cemconcomp.2009.04.003.

[33] Z. Fahrizal, S. Mohd Zailan, S. Eravan, The effect of mix design on mechanical and thermal properties oil palm shell (OPS) lightweight concrete, J. Civ. Eng. Res. 4 (2014) 203-207. 